EPJ Web of Conferences 114, 02085 (2016)

DOI: $10.1051 /$ epjconf/201611402085

(C) Owned by the authors, published by EDP Sciences 2016

\title{
Evaluation of thermal conditions inside a vehicle cabin
}

\author{
Tadeusz Orzechowski ${ }^{1, a}$ and Zbigniew Skrobacki ${ }^{1}$ \\ ${ }^{1}$ Kielce University of Technology 25-314 Kielce, Al. Tysiąclecia PP 7, Poland
}

\begin{abstract}
There are several important factors influencing road accidents. Temperature inside the vehicle is ranked third after alcohol and seat belts. For this reason, maintaining thermal comfort in the passenger compartment is essential. Thermal comfort is provided by the air conditioning system, which consumes much energy. In the case of electrically powered vehicles, this results in a shorter range. Optimization of such systems is therefore required. This paper proposes a set of equations describing the thermal conditions inside the vehicle, which are the result of appropriate energy balances for air, interior elements, and glass. Variable transmission conditions are included for transparent materials exposed to short and long wave radiation. The study focused on unsteady air-conditioning of the vehicle interior. The measurement data was compared with the results obtained through numerical solutions of the proposed set of equations.
\end{abstract}

\section{Introduction}

The beginnings of air conditioning go back to 1902, when Carrier designed and constructed a spray-type air washer, which was first applied to control the temperature and humidity of a publishing company. Since then, air conditioning has been defined as a process of supplying and maintaining desirable internal atmospheric conditions for human health and comfort. In the years that followed, the process was used first to improve the comfort within buildings and later also within motor vehicles. At the beginning, it was a relatively primitive, uncontrollable system. From 1933, it was installed in American luxurious limousines with powerful engines capable of handling additional load. After World War 2, Chrysler began installing such systems in series production cars. In the late 1960s, half of the cars produced in the US were equipped with such a system. In Europe and Asia, the American invention was perceived as a luxury car feature. This century it is becoming increasingly common in popular cars. Air conditioning is required when temperature is high; in the summer, when it frequently exceeds $30{ }^{\circ} \mathrm{C}$, air conditioning is even indispensable for the safe use of motor vehicles. These observations have been corroborated by findings on the relationship between road accidents and ambient temperature. Reference [1] considers the effects of several dozen different factors on accident frequency rates. The results show that alcohol is the most dangerous factor and temperature is reported to be the third.

Thermal comfort in enclosed spaces can be determined using, for instance, the Predicted Mean Vote (PMV) index developed by Fanger [2]. It describes human thermal impressions expressed in a seven-point scale from hot $(+3)$ to cold $(-3)$. It is recommended that the index value should not exceed \pm 0.5 , which corresponds to the percentage of occupants not satisfied with the indoor climate, known as the Predicted Percentage Dissatisfied (PPD), which, in turn, should not to be greater than $10 \%$. The temperature and humidity comfort is affected by the temperature and relative humidity of the air, the air flow velocity, and the temperature of the surrounding surfaces. However, these are not the only factors affecting the conditions required for thermal comfort. It is important to consider the following: the microbiological, particle and gaseous composition of air, air quality, lighting, noise, etc., as well as insulating effects of clothes, which are different in summer and winter. As shown in [3], the parameters are also dependent on the velocity of the moving vehicle.

As discussed in [4], some factors are difficult to predict; these include road conditions, environmental conditions, the mental and physical fitness of the driver, the driver's behaviour, etc. When considered, these factors relate the optimal comfort temperature with the air quality, which may lead to a decrease in energy consumption. Another study [5] shows that the local temperature and humidity comfort conditions have a considerable influence on the operation of the HVAC system in an electrically-powered vehicle. This reduces the driving range between recharging. An attempt was made to solve the problem, using the example of an electrically powered vehicle [6]. The thermal comfort model discussed in this work can be used to answer the questions concerning the effects of the environmental conditions on the range of electric vehicles, the requirements resulting from local climatic conditions, and the influence of air pre-conditioning to achieve the

\footnotetext{
${ }^{\mathrm{a}}$ Corresponding author: todek@tu.kielce.pl
} 
required comfort conditions before the journey on the vehicle range.

The effects of changes in the relative humidity of the cabin environment on the thermal comfort of the occupants were considered in [7]. From the thermodynamic and psychometric analysis it is evident that a change in the relative humidity can facilitate the process of air conditioning and reduce energy losses. The analysis results were represented graphically as PPD versus PMV. It was found that when the ambient temperature was high and the relative humidity of the air increased, there was a rise in the energy consumption of the air conditioning system. If the $\mathrm{AC}$ system is to be controlled effectively, it needs to take account of the relative humidity of the fresh air. However, air conditioning by evaporative cooling requires considerable changes in the system structure.

In another study [8], the tests were conducted on a group of fifty people, who were randomly selected to drive under three different climatic conditions: under cold, neutral and hot conditions, which corresponded to $5{ }^{\circ} \mathrm{C}, 20{ }^{\circ} \mathrm{C}$, and $35{ }^{\circ} \mathrm{C}$, respectively. In all the cases, the same relative humidity conditions of $50 \%$ were maintained. The best driver's performance was observed under neutral conditions. During the tests, which lasted 30 minutes, no influence of ambient temperature on the human body temperature and the heart rate was reported. However, the driving quality was very much affected by the driver's concentration, which declined significantly when the air conditioning parameters were controlled manually. Additionally, it was found that the manual selection of the direction of the air flow affected the thermal comfort of occupants and the efficiency of the HVAC system [9].

Investigations conducted in the climatic conditions of Paris [10] showed that the important factors affecting the temperature inside a vehicle with a large area of glazing were the solar radiation, the glass type, the vehicle colour, and the radiation properties of the interior materials. The mathematical model proposed by the researchers was based on the heat balance equation. However, it did not take into consideration the influence of the long-wave radiation caused by heated interior elements, i.e. the radiation almost entirely absorbed by transparent heat barriers, on the glass temperature, which can be responsible for certain discrepancies between the calculation results and the measurement data. A similar approach was used to calculate the thermal conditions in [11]. Despite the relatively good agreement between the calculation results and the measurement data, the researchers indicated that the model was not perfect because of the insufficient accuracy of the description of the radiation heat transfer inside the vehicle and the variable heat gains from the occupants attributable to the temperature and humidity conditions in the passenger compartment.

Different materials are used for the interior elements. Their physical properties are not always known. While determining dynamic changes in thermal conditions, we can improve the calculation accuracy by taking into account the thermal capacity of the interior elements and their materials and the radiation properties of different surfaces, especially their transmission and absorption properties $[12,13]$.

Air conditioning is a highly energy-consuming process, which leads to a higher consumption of fuel in conventional vehicles, and a shorter range in electric vehicles [14]. Possible solutions to this drawback include improving the efficiency of energy-storage systems and optimizing the operation of others, especially the heating and air-conditioning systems [15].

\section{Energy balance}

In this study it was assumed that, during unsteady-state heating or cooling of the vehicle passenger compartment, the interior was a space with uniform air flow conditions. With this assumption, the instantaneous temperature $T$ in time $t$ was determined from the following heat balance equation:

$$
\begin{aligned}
& m c_{p} \frac{d T}{d t}=m_{A C} c_{p}\left(T_{A C}-T\right)+m_{V} c_{p}\left(T_{V}-T\right)+ \\
& +m_{\mathrm{inf}} c_{p}\left(T_{a}-T\right)+\alpha_{i v}\left(T_{g}-T\right) A_{g}+ \\
& +\left(\alpha_{i h} A_{h}+\alpha_{i v} A_{v}\right)\left(T_{b}-T\right)+N q_{p 1}
\end{aligned}
$$

where $m$ is the cabin air mass and $c_{p}$ is the air specific heat.

The next terms on the right side of the heat balance equation denote: heat transferred to the interior air when the air conditioning is on, heat supplied with the ventilation air, heat from the air removed from the interior, heat from the surrounding surfaces due to convection phenomena, and heat from the occupants, respectively. The mass and temperature of the inlet air streams, $m_{A C}, m_{V}, m_{\text {inf }}$ and $T_{A C}, T_{V}, T_{i n f}$, respectively, can be determined from the parameter plots and recommendations on the settings of the HVAC system. These are: the mass and temperature of the air supplied by the air conditioning system $\left(m_{A C}, T_{A C}\right)$, the mass and temperature of the air supplied by the ventilation system $\left(m_{V}, T_{V}\right)$, the mass and temperature of the air entering the passenger compartment due to infiltration through open air blow ducts and other leaks $\left(m_{\text {inf }}, T_{\text {inf }}=T_{a}\right)$, the temperature of the transparent surfaces $T_{g}$ with surface areas $A_{g}$, and the temperature of other interior elements marked $T_{b}$. As the heat transfer coefficients differed in value, the surface area of the walls enclosing the passenger compartment space was considered according their direction: vertical $A_{v}$ and horizontal $A_{h} . \mathrm{N}$ is the number of occupants in the compartment, and $q_{p l}$ is the total heat, which is a sum of the sensible heat and the latent heat emitted by a single person. The temperature of the solid elements inside the passenger compartment (seats, instrument panel, etc.), $T_{b}$, present in Eq. (1) can be calculated from the following equation:

$$
\begin{aligned}
& C_{b} \frac{d T_{b}}{d t}=Q_{\alpha b}+Q_{r a d}= \\
& =\alpha_{b}\left(T-T_{b}\right) A_{b}+\varepsilon_{g} \sigma\left(T_{g}^{4}-T_{b}^{4}\right) A_{b} \approx \alpha_{b}\left(T-T_{b}\right) A_{b}
\end{aligned}
$$


where $C_{b}$ is the thermal capacity of the interior elements, $Q_{\alpha b}$ is the heat transferred by convection with the interior air, and $Q_{\text {rad }}$ is the heat gained (or lost) due to radiation through transparent heat barriers and radiation between solid elements and transparent barriers differing in temperature, e.g. the inside surface of the vehicle roof.

The solid parts include the seats, the floor, the instrument panel, etc. Because of their different location in the passenger compartment space, they are subjected to different direct radiation of the sun, and accordingly, they may differ in temperature. This is particularly true about the instrument panel. It is thus more convenient to determine the average air temperature and the heat transfer coefficient $\alpha_{b}$.

Radiation may affect materials. The effects are dependent on the wavelength and angle of radiation as well as the optical properties of the material. In the case of spaces enclosed with glass elements that are transparent for short-wave radiation and almost entirely absorb long-wave radiation, the thermal load caused by solar radiation is calculated for the two components separately $[16,17]$ : short-wavelength $(\mathrm{SW})$ radiation for the spectral range $\lambda \leq 2.5 \mu \mathrm{m}$ and long-wave (LW) radiation for $\lambda>2.5 \mu \mathrm{m}$. Thermal effects in the long wavelength range are characteristic of diffuse and reflected radiation and low temperature bodies.

Assuming the glass thickness $h_{g}$, glass density $\rho_{g}$ and glass specific heat $c_{g}$, we can calculate the change in temperature $T_{g}$ over time from the following equation:

$$
\begin{aligned}
& h_{g} \rho_{g} c_{g} \frac{d T_{g}}{d t}=\alpha_{e}\left(T_{a}-T_{g}\right)+ \\
& +\alpha_{g s w} I_{s w}+\alpha_{g l w} I_{l w}+\alpha_{i}\left(T-T_{g}\right)+ \\
& +\alpha_{g l w} \sigma T_{b}^{4}-2 \varepsilon_{g} \sigma T_{g}^{4}+\alpha_{g l w} I_{n}
\end{aligned}
$$

It should be noted that, for a moving vehicle, the heat transfer coefficient on the outside $\alpha_{e}$ is dependent on the actual velocity of the air. The coefficient is determined from an appropriate relationship for the Nusselt number, i.e. for forced convection, when the vehicle is moving, and for natural convection, when the vehicle is stopped [16]. I denotes radiation intensity in the SW or LW range. The radiation absorption coefficient for radiation absorbed by the glass in the appropriate spectral range was denoted by $\alpha_{g} . I_{n}$ is the intensity of the solar radiation, whose spectrum is in the LW range. For air with temperature $T_{a}$ containing water vapour whose amount is defined by its partial pressure $p_{H 2 O}$ (in $\mathrm{hPa}$ ), this quantity can be calculated using the StefanBoltzmann law, in which the temperature of the sky $T_{n}$ is determined from the formula:

$$
T_{n}=T_{a} \sqrt[4]{0.526+0.065 \sqrt{p_{\mathrm{H}_{2} \mathrm{O}}}}
$$

The windscreen also radiates energy. Assuming that the glass is optically grey, its value is determined by means of the specific emission coefficient $\varepsilon_{g}$. An appropriate term describing this quantity is included in the heat balance equation (3).
The proposed model takes account of the radiation effects related to the emission and absorption properties of the surrounding surfaces [13]. Additionally, it can be used to optimize the operation of the evaporator in an automotive AC system, which is achieved by microscale surface enhancement in systems where the principle of operation involves the phase change of the refrigerant $[18,19]$ in different boiling regimes: from nucleate to film boiling $[20,21,22]$. The model, which is based on a system of three differential equations, can be employed to optimize the control of the automotive HVAC system, and accordingly, to improve the fuel economy or increase the range [23]. This approach is particularly important for electrically-powered vehicles.

\section{Test results}

The tests were conducted on a Suzuki SX4 equipped with a manufacturer - installed manual single-zone air conditioning system. In this vehicle, the air flow parameters are selected with two knobs: one for turning the temperature up or down (continuous mode), and the other for changing the position of the fan speed setting (step mode). In the case of the latter, there are four positions of the fan speed corresponding to four air flow rates. The air coming from the blower can be directed only towards the windscreen, both towards the windscreen and the upper or lower zone of the internal space through a system of directional panel vents and floor vents. Their location is shown in the schematic diagram in figure 1.

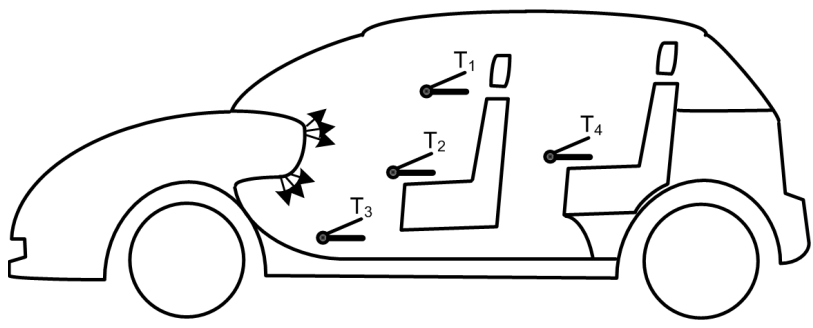

Figure 1. Location of the thermocouples in the passenger compartment.

The parameters of the cooled air supplied to the interior were measured by setting the air conditioning system at the lowest temperature with the air flow directed towards the head and the feet. The temperature was registered at four different positions of the fan speed (positions I to IV). The temperature and velocity of the air blown inside were measured with a thermocouple sensor vane anemometer. The resolution of the temperature readings obtained with the meter was $0.1 \mathrm{~K}$, while its accuracy was $\pm 0.5 \mathrm{~K}$. The corresponding values for the measurement of the incoming air flow velocity were: resolution $0.01 \mathrm{~m} / \mathrm{s}$ and accuracy $\pm 0.1 \mathrm{~m} / \mathrm{s}$. The sensors were placed in the plane of two panel grilles with the air directed towards the head. Each measurement was repeated several times. Their average values are shown in Table 1. 
Table 1. Air temperature and air flow velocity at four different positions of the fan speed.

\begin{tabular}{|c|c|c|}
\hline Setting & $\begin{array}{c}T_{\text {mean }} \\
{ }^{\circ} \mathrm{C}\end{array}$ & $\begin{array}{c}V_{\text {mean }} \\
\mathrm{m} / \mathrm{s}\end{array}$ \\
\hline I & 9.2 & 0.45 \\
\hline II & 12.35 & 0.97 \\
\hline III & 14.6 & 1.7 \\
\hline IV & 17.3 & 2.81 \\
\hline
\end{tabular}

The temperature of the outside air was constant at about $30.5^{\circ} \mathrm{C}$ before cooling. After cooling, its value was strongly dependent on the air flow velocity. At the lowest fan speed (control knob in position I), it was at about $9.2^{\circ} \mathrm{C}$, while at the highest it rose to $17.3{ }^{\circ} \mathrm{C}$.

After a longer period of non-operation at hot summer temperatures, with the vehicle parked in full sun, the interior air reaches a temperature at which the driver's performance drops. Under such circumstances, the air needs to be cooled immediately, which is achieved by switching on air conditioning. The system can operate in different modes. One of the parameters to control is the blower speed. The speed affects the temperature of the incoming fresh air. Thus, thermal conditions not only change over time but they are also dependent on the parameters set. Five thermocouples were mounted inside the passenger compartment to monitor them; a sixth one was used to measure the temperature of the outside air. The first of the thermocouples was employed to measure the temperature at the driver's head level $\mathrm{T}_{1}$. The second determined the temperature at the driver's knee level $\mathrm{T}_{2}$. Temperature $\mathrm{T}_{3}$ was measured at the feet level. Two thermocouples were placed at the back to measure the temperature at the knee level for passengers occupying the rear seat (in figure 1 , both marked $\mathrm{T}_{4}$ ). All the sensors were linked to the data acquisition station, which was programmed to register all signals with the same frequency of $1 / 15 \mathrm{~Hz}$ (four measurements per minute). Before the tests, the vehicle was parked in full sun and then travelled about $5 \mathrm{~km}$ to heat the engine so that, when switched on, the air conditioning system could operate in steady state thermal conditions. Next, the vehicle was parked in the shade and the measurement of temperature commenced.

In the first series, the fan speed control knob was placed in position I, which corresponds to the minimum capacity of the fan. After about 7 minutes, the fan was turned off, the interior was aired thoroughly, and then the fan control knob was placed in position II. Measurements were taken after about 7 minutes, with all the doors closed. The test results are illustrated in figure 2 . a)

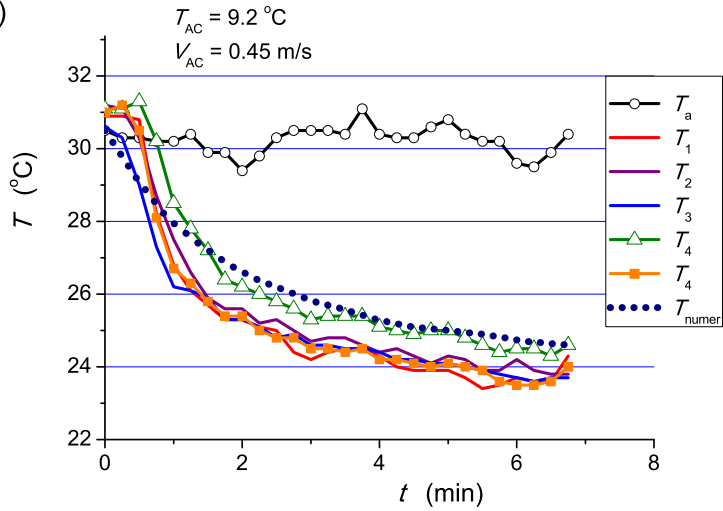

b)

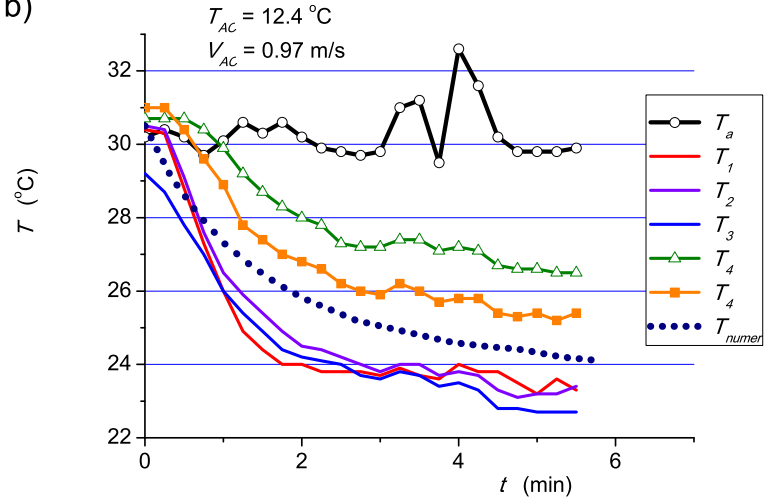

Figure 2. In-vehicle temperature plots for different points in the compartment (see figure 1) and the ambient temperature plot $T_{a}$, with the blower fan control knob placed in a) position I, b) position II.

In the first series, the fan speed control knob was placed in position I, which corresponds to the minimum capacity of the fan. After about 7 minutes, the fan was turned off, the interior was aired thoroughly, and then the fan control knob was placed in position II. Measurements were taken after about 7 minutes, with all the doors closed. The test results are illustrated in figure 2 .

\section{Result analysis}

The flow of the air blown into the passenger compartment can be blended, low turbulent or laminar in nature. The division is dependent on the degree of turbulence of the air stream, understood as the ratio of the time-averaged pulsation velocity to the average flow velocity.

When the turbulence is higher than $20 \%$, extensive blending occurs at the stream threshold between the air blown into the compartment and the interior air. This leads to an increase in the amount of air in the stream with an increase in the distance from the air inlet opening. In the low turbulent flow, with the degree of turbulence between 10 and $20 \%$, cold air flows in and causes the warm interior air, which absorbed heat from the surrounding objects, to go up by convection. As a result, the differences in temperature in the vertical crosssection are reduced considerably. A laminar flow is characteristic of very small and steady-state flow velocities, lower than $0.4 \mathrm{~m} / \mathrm{s}$; to keep it, it is necessary to 
maintain steady state conditions of the inflow of fresh air. This type of the air conditioning of the vehicle interior is achieved when the blower is off, the driving velocity is constant and the conditions outside the vehicle are steady.

Figure 2 shows plots of temperature registered at different points of the passenger compartment; the measurements were taken by changing the fan speed only, which resulted in different air flow velocities. With a relatively small air flow velocity and the fan speed set at a minimum, the air stream directed towards the heads of the occupants in the front seats does not reach the heated parts of the ceiling. As the cool air is heavier than the air in the upper zones of the passenger compartment, it falls towards the floor. After being slightly heated there, it is forced up by convection to the upper parts of the compartment. The phenomena are characteristic of the low turbulent air flow, which results in a uniform distribution of temperature inside the passenger compartment.

In the second series of the measurements, when the fan speed was higher, the average velocity in the instrument panel plane doubled. This results in a strongly turbulent flow. Air is directed down towards the occupants' feet and up towards their heads. Since the tests were conducted for an empty vehicle, with no occupants in the passenger compartment, the air stream moved freely to the ceiling and then parallel to it. Its temperature was higher than the ambient temperature so the air stayed in the central part of the compartment. The temperature measured at the knee level at the back for passengers occupying the rear seat was 3 to 4 degrees higher than that reported at the front. This is likely due to the hindered flow of cool air under the front seats from the front to the rear part of the passenger compartment. In the front part of the compartment, however, no considerable changes in temperature were reported in the vertical cross-section.

Ambient temperature, plotted in figure 2, was an independently measured quantity. The measuring thermocouple was placed directly at the data acquisition station near the front door at the doorstep level. The measurements were carried out in a relatively short period of time so that the ambient temperature remained almost steady at about $30.5{ }^{\circ} \mathrm{C}$. As it was necessary to maintain steady-state operating conditions of the $\mathrm{A} / \mathrm{C}$ system, the tests were performed on a preheated engine. While running under such conditions, the engine got very hot; as a result, every now and then, the fan switched on automatically to draw the air through the radiator and blow it over the engine surface. Some of the air flew as far as the sensor. As can be seen in Fig. 2, an instantaneous increase in temperature was registered then.

Equations (1), (2) and (3) describe the time-dependent temperature of the cabin air, the cabin equipment, and the windows, respectively. For the test conditions, the system was solved numerically. For both analyzed settings of the air blower, the calculation results were plotted in figure 2 . The discrepancies between the measurement data and the calculation results are due to the simplifying assumptions made in this study.
From the study it is clear that at the predetermined control settings, the most uniform and, accordingly, the most favourable distribution of the cabin air temperature occur at low turbulent flow. This corresponds to the minimum capacity of the blower in the HVAC system.

It is important to note that the measurements were performed on a parked vehicle with the engine switched off and no occupants inside. The presence of a driver and one or more passengers would have definitely changed the cabin air flow. However, it seems that the physical phenomena related to the nature of the air flow and the influence of the air flow on the temperature distribution would have been similar.

\section{References}

1. Th.-J. Zlatoper, Accid. Anal. Prev., 23, 5 (1991)

2. P.O. Fanger, Thermal comfort (Arkady, Warszawa, 1974) (in Polish).

3. J. Fišer, J. Pokorný, EPJ Web of Conferences, 64 (2014)

4. H. Khayyam, Appl Therm Eng., 51 (2013)

5. K.R. Kambly, T.H. Bradley, J Power Sources, 259 (2014)

6. K.R. Kambly, T.H. Bradley, J Power Sources, 275 (2015)

7. A. Alahmer, M.A Omar, A. Mayyas, S. Dongi, Appl Therm Eng, 31 (2011)

8. H.A.M. Daanen, E. Vliert, Xu Huang, Appl Ergon, 34 (2003)

9. J. Fišer, M. Jícha, EPJ Web of Conferences, 45 (2013)

10. A. Mezrhab, M. Bouzidi, Appl Therm Eng, 26 (2006)

11. D. Marcos, F. J. Pino, C. Bordons, J. J. Guerra, Appl Therm Eng, 66 (2014)

12. J. Pokorny, J. Fišer and M. Jicha, EPJ Web of Conferences, 64 (2014)

13. T. Orzechowski, K. Ziętala, District Heating, Heating, Ventilation, 45/8 (2014)

14. K.R. Kambly, T.H. Bradley, J Power Sources, 259 (2014)

15. J. Fišer, J. Pokorný, M. Jícha, EPJ Web of Conferences, 25 (2012)

16. F. P. Incropera, D.P. DeWitt, T.L. Bergman, A.S. Lavine, Fundamentals of Heat and Mass Transfers (John Wiley \& Sons Inc., U.S.A, 2006)

17. T. Kruczek, Energy, 91 (2015)

18. T. Orzechowski, Exp Therm Fluid Sci, 31 (2007)

19. R. Pastuszko, Int J Therm Sci, 49 (2010)

20. T. Orzechowski, A. Tyburczyk, EPJ Web of Conferences, 67 (2014)

21. T. Orzechowski, S. Wciślik, Int J Heat Mass Tran, 73 (2014)

22. R. Pastuszko, T. M. Wójcik, Exp Therm Fluid Sci, 63 (2015)

23. Z. Skrobacki, Maintenance and Reliability, 3 (2007) 